\title{
Effect of Boundary Layer Fence Location on HAWT Power Performance
}

\author{
Sundaravadivel Arumugam1, Nadaraja Pillai Subramania², Senthilkumar Chidambaram ${ }^{1}$ \\ ${ }^{1}$ Department of Aerospace Engineering, Madras Institute of Technology, Anna University, Chennai, India \\ ${ }^{2}$ School of Mechanical Engineering, SASTRA University, Thanjavur, India \\ Email: aerovelu@gmail.com
}

Received 18 March 2016; accepted 30 May 2016; published 2 June 2016

Copyright (C) 2016 by authors and Scientific Research Publishing Inc.

This work is licensed under the Creative Commons Attribution International License (CC BY).

http://creativecommons.org/licenses/by/4.0/

(c) (i) Open Access

\begin{abstract}
Even though wind energy is a deep-rooted technology, but not yet mature and hence there are bounteous scopes for improvement to reduce the cost of wind energy. An experimental investigation has been carried out on 1:25 scaled 5809 aerofoil blade featuring boundary layer fence at various span wise location. Quantifying electrical power obtained by rotation of wind turbine rotor coupled with dynamic testing system. A baseline model with no flow control and an upgraded model with detachable boundary layer fence have been studied in the wind tunnel. For upgraded model, fences were placed along the location of $40 \%$ to $90 \%$ of the blade span. The rotor blades are then tested dynamically in wind tunnel at open terrain condition for $7 \mathrm{~m} / \mathrm{s}, 9 \mathrm{~m} / \mathrm{s}$ and $11 \mathrm{~m} / \mathrm{s}$ velocities. In order to study the effect of boundary layer fence test has been carried out in the low speed wind tunnel having test section of size $0.9 \mathrm{~m} \times 1.2 \mathrm{~m} \times 2 \mathrm{~m}$. Scope corder DL 750 is used to measure time varying voltage and proximity sensor with its compatible display unit is used to measure the rotor RPM. The flow behaviour was found to be considerably favourable from conventional rotor blades. Installation of fence has been found promising for increased energy extraction from air column by controlling the three dimensional span wise flow. Results demonstrate the potential of the proposed model which can obtain a maximum of about $11.8 \%$ increase in the power. In addition, the significance of the location of wing fence and blade pitch angle has been analysed.
\end{abstract}

\section{Keywords}

HAWT, S809 Airfoil, Boundary Layer Fence, Wind Tunnel Testing

\section{Introduction}

In recent years, wind energy has emerged as one of the most reliable means of producing large quantities of 
power in the field of renewable energy technology. In order to improve the economic viability of the wind turbines, wind energy projects should concentrate on efficient energy capture out of the rotors. As most of the wind turbines have restrictions on rotor diameter in some form or another, the only way the power production can be optimized at any specific wind velocity is through maximizing the $C_{p}$ of wind turbine (Johansen et al. [1]). Improving $C_{p}$ without increasing the projected area can be optimized by the use of passive and active boundary layer tripping device. Several methods of controlling boundary layer separation have been developed experimentally with the aid of theoretical considerations. Because of similarity of flows, some methods of minimizing energy losses in aircraft application are directly applicable to wind turbines. A significant improvement in rotor performance may be realized by applying aerodynamic principles that have been successfully used to minimize separation losses in the flow over the wings. In general flow separation and its corresponding energy losses are caused by the flow of retarded fluid particles near the surface of the rotors. Control of flow separation is necessitated because conventional designs of wind turbines normally lead to severe flow separation over a considerable portion of the rotor blades. This separation results in a degradation of the flow quality and consequently diminishes energy production. According to IEA's estimation, wind energy will contribute $12 \%$ of the total energy requirement [2]. Also, the experts predict that the wind power would capture $5 \%$ of the world energy market by the year 2020 [3] [4]. IEA further estimated that usage of Wind Energy helps lowering the greenhouse gas emissions [5]-[7]. Therefore, it is a logical time to investigate modifications to improve the Wind turbine performance. Ultimately, such improvement yields increased power production catering to the growing energy demands.

Taehwan Cho [8] et al. demonstrated that wind tunnel test is a major tool for the aerodynamic configuration development of an aircraft and also indispensable for the aerodynamic study of the wind turbine blade. Even though most of the studies for the wind turbine blades are conducted by the computational methods, the experimental research is still needed for the development and validation of the computational model. The experimental approach for the wind turbine blade is restricted by the size of the blade model. Therefore, it is necessary to use the scaled down model for the experimental studies of the wind turbine blade. Usage of scaled down models lead to scaled effect. The scaled effects are outrun by the advantages which are provided by the scaled down model. The significance of using the scaled down wind turbine models was discussed in detail by Caro L. Botasso [9] et al., His work clearly demonstrates that the scaled model holds better control and knowledge of the testing conditions, error and disturbances. Furthermore, it is possible to perform measurements which might not be feasible at full scale, and the testing typically incurs in much lower cost. The scaled testing does not replace simulation or field testing, but works in synergy with both towards the improved knowledge of the problem at hand. Being drawn the national attention towards the renewable energy enough care should be taken to minimize the detrimental effects caused by the wind turbine to the environment. One of the major environmental concerns that must be addressed when building wind farms is the impact the wind turbines will have on the local animal population. Baerwald [10] et al., at the University of Calgary show that bat deaths previously believed to be caused by birds striking the rotating blade are in fact due to capillaries within the bird's lungs bursting. This phenomenon is attributed to the animals encountering a substantial pressure difference while flying near the wind turbine blades. Further investigation has led to hypotheses that such a drastic pressure drop would likely occur only near the blade tip, within the wing tip vortex. Additionally, research is currently being conducted within the research community to explore methods of minimizing the circulation effect to increase the efficiency of the wind turbines.

Flow control is one of the leading areas of research of many scientists and engineers in Fluid mechanics. Flow control involves passive or active devices that have a beneficial change in the flow field. A passive flow control (PFC) is a method in which a flow is modified without external energy expenditure. Passive techniques include geometric shaping to manipulate the pressure gradient, the use of fixed mechanical vortex generators for separation control, and placement of longitudinal grooves or riblets on a surface to reduce drag. In Contrast, Active Flow Control (AFC) is a method in which energy, or auxiliary power, is introduced into the flow. Many researches had been carried out to change the flow behaviour over the blade surface from past years. Shane Merchant [11] et al., confront that by designing and testing, proper flow control devices the instances of bat deaths can be decreased as well as increasing the efficiency of wind turbine blades. Shane focussed on adding winglets to the wind turbine blade. Additionally Johansen [1] et al., and Jeppe [12] et al., experiments also found that addition of properly designed winglet results in the reduction of drag force and expected to increase the power output. Michael D. Williams [13] et al., demonstrated an approach to improve the stall characteristics of an airplane 
wing with the addition of a wing fence. Wing fences have been used to improve the aircraft's high angle of attack performance and approach to stall characteristics. It is illustrated that the formation of a discrete stream wise vortex outboard of the fence prevents the flow separation in the tip region, which in turn delays the flow separation over the reminder of the wing, resulting in the higher lift. Overall, Michael D. Williams [13] et al. reported in detail, the usefulness of boundary layer fence to reduce the intensity of 3-D span wise and separated flow outboard the fence for aircrafts. Even though there were many active flow control methods and passive flow control methods are available to improve the efficiency of HAWT, the use of Boundary Layer Fence in HAWT has not been reported yet. In this paper, research is focussed on implementing the wing fences to enhance the efficiency of wind turbine blades. The wind turbine blade is also having a similar aerodynamic shape as of an aircraft wing. Both the aircraft wing as well as wind turbine blades have a similar phenomenon of pressure difference and 3 dimensional effects. Hence fence can be installed in the wind turbine blades in order to control the 3 dimensional flow effect. In addition to the installation of the fences can be made with little or even no structural change to the wing. Retrofitting of the wing fences can also be made with ease in wind turbines. Several investigators Bumsuk Kim [14] et al., and Jing Li [15] et al., etc. used BEM theory to evaluate their wind turbine design for base line model but wind tunnel or field experiments are found to be the best way of evaluating the modified rotor performance.

\section{Experimental Methodology}

In the present study, models were designed with the goal of supporting experimental observations in wind turbine aerodynamics. The need to support these diverse applications dictated a number of specific design requirements which includes;

- A realistic energy conversion process enabled by good aerodynamic performance at the aerofoil and the blade level translating in to reasonable power production

- Dimensions of the models as large as possible, to avoid excessive miniaturization which would complicate the realization of flow control capabilities.

- On the other hand, the rotor dimension should not cause excessive blockage effects due to interference with the wind tunnel walls.

- A comprehensive and dynamic testing system to measure the electrical output power produced as a result of the wind turbine rotation due to wind flow. It should be capable of measuring the voltage values with respect to time for all the measurements.

\subsection{Blade Design and Fabrication Requirements}

The experimental model was designed based on the NREL phase VI rotor model having a full scale rotor diameter $10.058 \mathrm{~m}$. In order to keep blockage below $5 \%$ of test section area, the model rotor diameter was taken as $40 \mathrm{~cm}$, leading to a geometric scaling factor of 1:25. The height of the turbine blades was set to $20 \mathrm{~cm}$, the detailed dimensions were given in [16]. The blade design includes a linear taper and non linear twist distribution with S809 aerofoil sections which requires a special machining process to produce the necessary twist and taper accurately. Three Dimensional 5 Axis profile milling machine is used for manufacturing a master blade. Because of lightweight and better machine ability, the master blade is made up of aluminium. The working blade is fabricated through moulding process by Fibre Reinforced Plastic (FRP) material by using the master blade as a pattern. The nomenclature of the fence has been shown in Figure 1. The baseline model has been upgraded with the Boundary layer fence to test its aerodynamic loads due to the expected presence of substantial span wise flow. The baseline model mounted with the wing fences forms the upgraded model, i.e. the wing fences are made separately as a detachable model and can be mounted over the blade on need.

\subsection{Experimental Facility and Dynamic Testing System}

Experiments are conducted in the low speed open circuit wind tunnel with Turbulence Intensity of $0.1 \%$, in which the fan speed can be varied in steps of 1 RPM. The wind tunnel has a rectangular test section with a cross sectional area of $0.9 \mathrm{~m} \times 1.2 \mathrm{~m}$ and length of $2 \mathrm{~m}$ and a maximum speed in the test section is $40 \mathrm{~m} / \mathrm{s}$, the test section is equipped with multi channel pressure scanner which can measure simultaneous pressure measurement with the sampling frequency of $325 \mathrm{~Hz}$. The tunnel is powered by the speed controlled electrical motor that 
drives Propeller. Inlet guide vanes at the entrance of the contraction, a honeycomb and screens are put upstream of the test section to maintain appropriate flow quality. Additionally, dynamic testing system was developed to measure the electrical output power produced as a result of the wind turbine rotation due to wind flow in the test section of the wind tunnel. The testing system had been instrumented with a 6V D.C Generator, which is fitted in the nacelle; wind turbine rotor model assembled in the generator shaft, a decade resistance box, an ammeter, Rpm measurement sensor with an indicator and Yokogawa scope corder-DL 750. Predescu [17] et al. used a similar circuit to measure the influence of the number of blades on wind turbine performance. Initially, the wind turbine blade models were mounted on the generator shaft and the output of the generator is connected in a circuit as shown in Figure 2 to measure the electrical output power produced as a result of the wind turbine rotation due to wind flow. A Decade Resistance Box (DRB) is used to vary the resistance in the circuit so that the effect of resistance over the model can be studied.
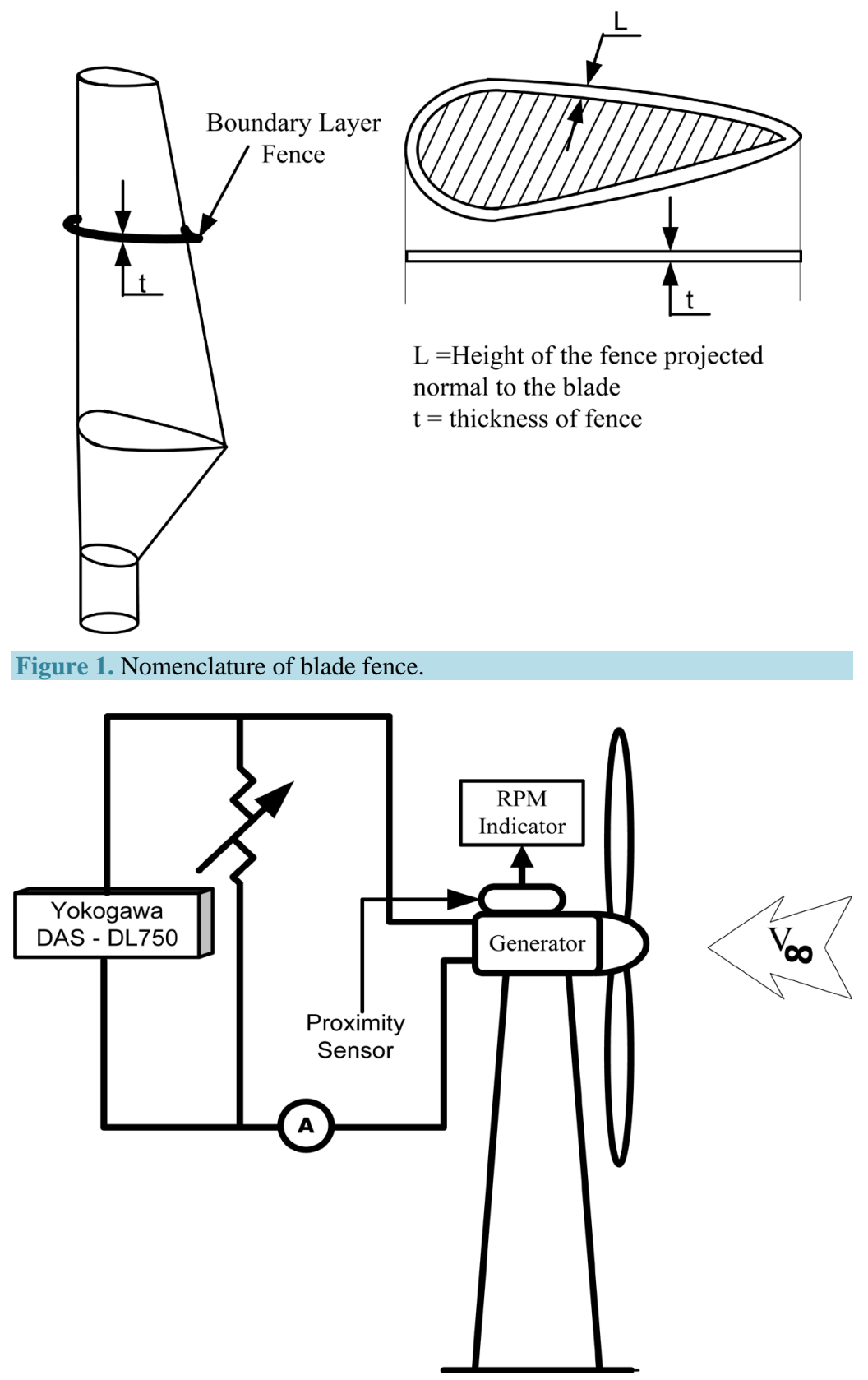

Figure 2. Circuit diagram-dynamic testing system. 
The experiment is conducted to find the effectiveness of the resistances in the circuit by measuring the voltage and amps due to varying the resistance in a wide range of 0 to 4000 ohms using DRB is executed. A wide variation in voltage and amps were found due to the variation of resistance in the range of 100 ohms to 1000 ohms. The tests were conducted by varying 3 different resistance values $100 \mathrm{ohms}, 400 \mathrm{ohms}$ and $700 \mathrm{ohms}$ and the corresponding current and voltages are measured. In order to record time varying voltage, Scope corder is connected to the circuit as shown in Figure 3. Voltage values with respect to time had been recorded for 30 second duration for all the measurements at a sampling frequency of 300 samples per second.

A digital multimeter is installed in the circuit to measure the current. The wind turbine rotational speed is measured with a proximity sensor connected to a digital display. The sensor is set to sense a metal needle attached to the hub of the turbine rotor. Once the effect of resistance on power production has been analysed, the scaled down model of the conventional rotor model, i.e. the baseline model is tested at 3 different air speeds (say $7 \mathrm{~m} / \mathrm{s}, 9 \mathrm{~m} / \mathrm{s}$ and $11 \mathrm{~m} / \mathrm{s}$ ) and the generated electric power is measured utilizing the dynamic testing system. Following that, to analyse the effectiveness of the wing fences and its location on the wind turbine blade the upgraded model is mounted on the test section. Then boundary layer fence of $1 \mathrm{~mm}$ thickness had been installed in a different span wise locations $\mathrm{r} / \mathrm{R}=0.9,0.8,0.7,0.6,0.5$ and 0.4 its effectiveness is studied by testing it under the conditions similar to the previous one.

In all these cases, the power output measurements are performed using the dynamic testing system, which helps understanding the effect of the location of the wing fences on wind turbine blades. The wind turbine rotor model assembled in wind tunnel is shown in Figure 4.

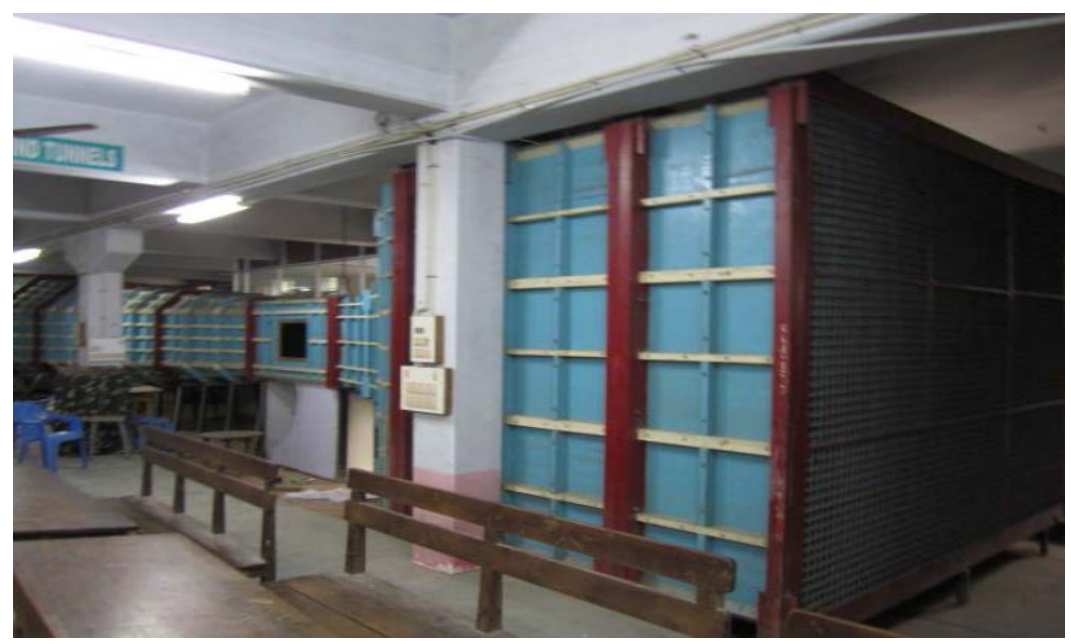

Figure 3. Low speed wind tunnel.

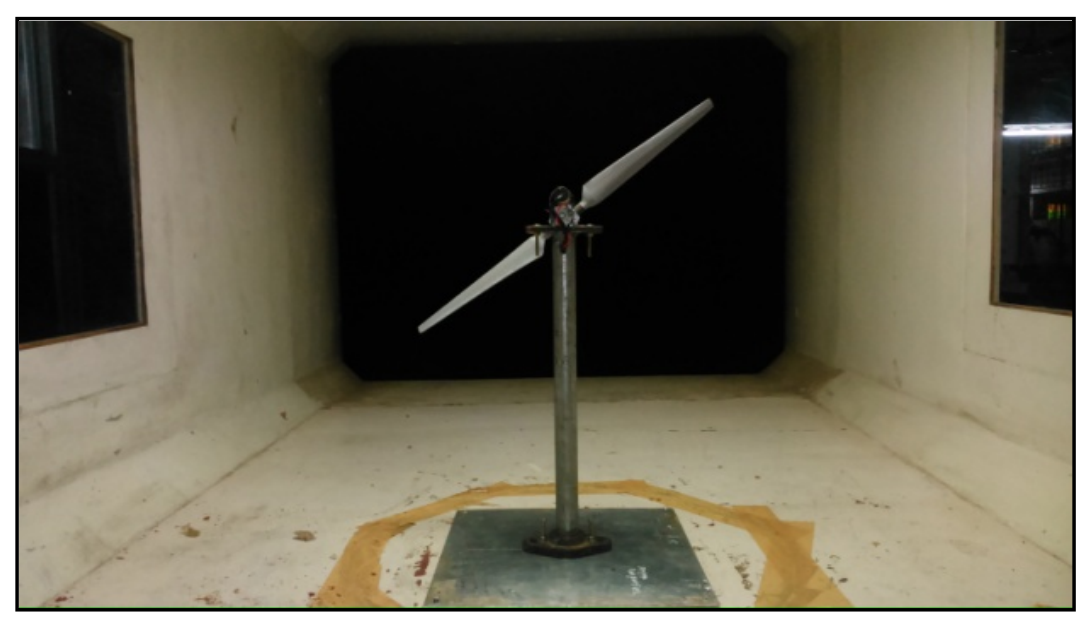

Figure 4. Experimental model in wind tunnel. 


\section{Data Accuracy}

Scope corder, which is used to measure the voltage in time series have an accuracy of $\pm 0.25 \%$. The display unit which is used to measure RPM is accurate to 2 decimal places. To obtain a stable output, the RPM measuring unit needs at least 30 seconds, so far all the test cases, air flow is allowed to stabilize for 30 seconds to 1 minute and then the readings are taken. The blade pitch angle has been changed from $0^{\circ}$ to $30^{\circ}$ in steps of $5^{\circ}$. These angles are marked in turbine hub and another marking is provided in the blade. Marking provided on the blade is made to coincide with the corresponding markings of angles manually for which the experiments are performed. There is a chance for manual error and it can be eradicated by providing an automatic angle changing mechanism in future. Machining of the prototype had been done in 5 axis milling machine and it has been replicated in FRP. Chance for error in this regard is very minimum.

\section{Results and Discussions}

Wind turbine blades fitted with Boundary layer fence were tested in the experimental facility available at Madras Institute of Technology, Chennai. Installation of wing fences produced a promising increase in power performance. This is most likely due to the fact that the wing fence acts as a barrier, preventing the growth of a span wise and separated flow outboard the fence. The effect of the fence is discussed in detail in the following section.

\subsection{Effect of Resistance Change}

Experimental investigations were performed to find out the effect of resistance on the increase in power for different blade pitch angles. Multiple resistances have been considered for experimental observation and experiments were carried out on the rotor blade fitted with fence having thickness of $1 \mathrm{~mm}$ at different span wise locations. It is evident from the result that the 700 ohms resistance stands out among the rest of the resistances contemplated i.e. 400 ohms and 100 ohms. When the greatest resistance is applied, it will create an impact on the generator and forces the generator to rotate at a much higher rpm which will induce a mechanical stress on the generators. The rotor blades have to sweep the atmospheric air at a much greater rate than before to relieve the mechanical stress induced in the generator. This dictates that higher resistance results in peak rpm. However, as expected, the maximum power performance observed is at $700 \mathrm{ohm}$ resistance, followed by decrease in power for further low resistances. The explanation of this effect is based on the load applied to the wind turbine rotor blades. The greater the resistance offered in the electrical system greater will be the load implied on the turbines to produce power output. The relation between the blade rotational velocities relative to the local wind speed also depends upon the resistance change on the wind turbines. The effect of resistance change over the $\%$ of power has been studied. At 50\% span location, for $7 \mathrm{~m} / \mathrm{s}$ velocity the peak power is associated with the blade pitch angle of 20 degree which yields $11.4 \%$ increase in power for $700 \mathrm{ohm}$ as shown in Figure 5. Simultaneously $400 \mathrm{ohm}$ resistance produces 10.2\% increase in power as displayed in Figure 6 whereas 100 ohm resistance harvests $8.9 \%$ increase in power which can be seen from Figure 7. Likewise, increase in \% of power

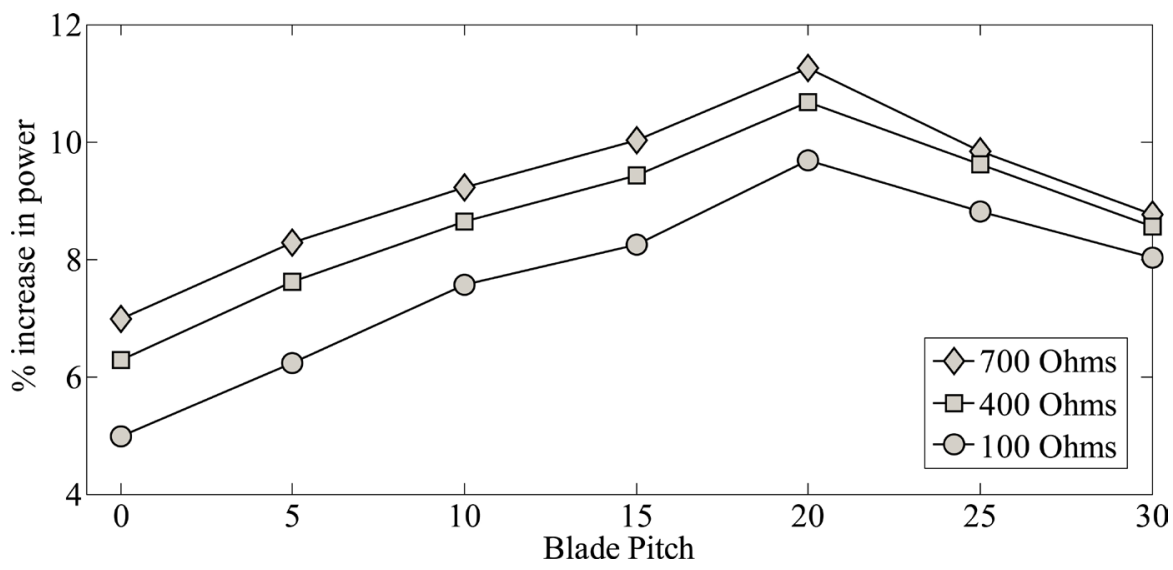

Figure 5. Effect of resistance change $7 \mathrm{~m} / \mathrm{s}$ velocity - fence $\mathrm{L} / \mathrm{t}=1$ at $50 \%$ span. 


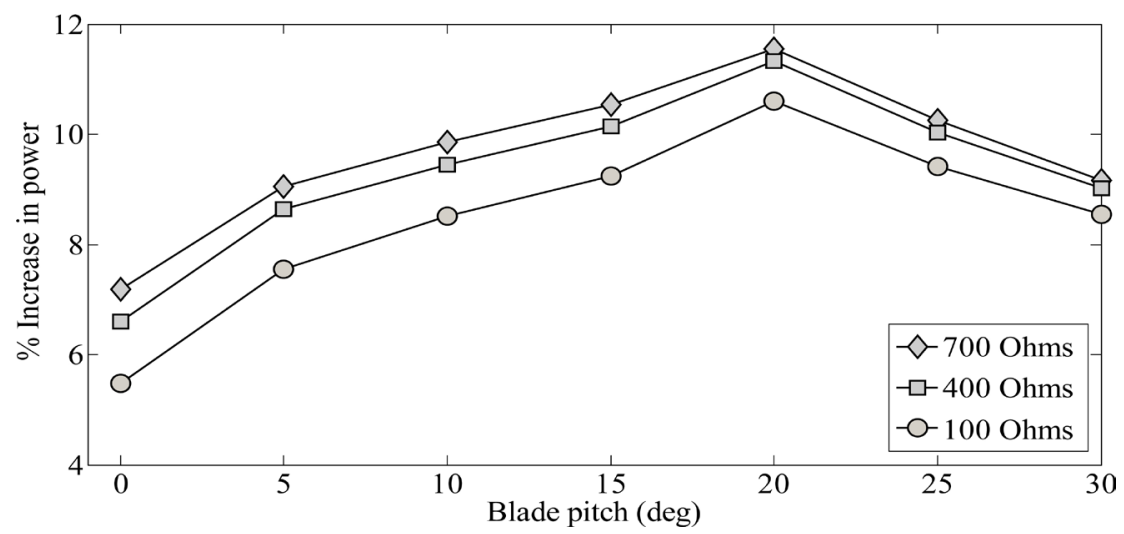

Figure 6. Effect of resistance change $9 \mathrm{~m} / \mathrm{s}$ velocity - fence $\mathrm{L} / \mathrm{t}=1$ at $50 \%$ span.

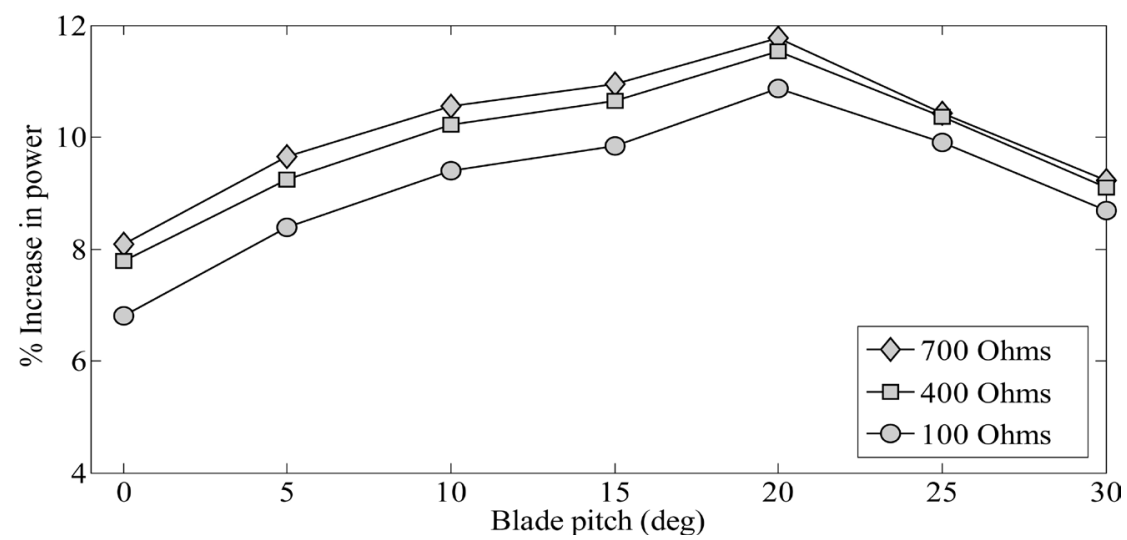

Figure 7. Effect of resistance change $11 \mathrm{~m} / \mathrm{s}$ velocity - fence $\mathrm{L} / \mathrm{t}=1$ at $50 \%$ span.

production at various velocities has been estimated as $11.6 \%, 10.9 \%$ and $9.8 \%$ for $9 \mathrm{~m} / \mathrm{s}, 11.88 \%, 11.51 \%$ and $10.31 \%$ for $11 \mathrm{~m} / \mathrm{s}$ respectively. It gives a clear picture that higher resistances provide a commendable rise in percentage of power. A Similar trend has been observed in other span wise locations also. Further, the results prove that power performance decreases with the least resistance. Even though the trend of power output and resistances is same, the free stream velocity, blade pitch angles and span wise fence locations have its own impact on the power production.

\subsection{Effect of $\mathrm{r} / \mathrm{S}$-Fence Location on Power}

It is evident from the research that the installation of the wing fences increases the power production. In order to deduce the effect of fence location, fences have been placed at various span wise locations, observations were carried out for wind turbine blades with fences at several span locations based on the factor entitled $\mathrm{r} / \mathrm{S}$ (ratio of radius at which the fence is installed to the overall blade span). The blade with fences positioned at various $\mathrm{r} / \mathrm{S}$ is shown in Figure 8.

Observations are carried out from $r / S=40 \%$ of the span to $r / S=90 \%$ of the span and the increase in power production has been calculated using Equation (1).

$$
\% \text { of Increase in power }=\frac{P_{u}-P_{c}}{P_{c}} \times 100
$$

Wing fences installed at various locations produce a significant increase in power production. The graphs were plotted between the percent of increase in power with respect to the pitch angle for various fence locations. Observations were carried out for wind turbine blades with fences at several span locations based on the factor entitled $\mathrm{r} / \mathrm{S}$. The factor $\mathrm{r} / \mathrm{S}$ shows the resistance along the span wise distribution. In order to deduce the effect of the location of the wing fence the observations are carried out at wide ranges from $r / S=40 \%$ of the span to $r / S=$ 
90\% of the span as shown in Figure 8. The graphs delineate that the $\mathrm{r} / \mathrm{S}=50 \%$ produces the maximum impact on power production, which is evident from the values observed. Figure 9 depicts that $r / S=90 \%$ produces a power output of $9 \%$, while the $\mathrm{r} / \mathrm{S}=50 \%$ power output of $11.4 \%$ which is the maximum at $7 \mathrm{~m} / \mathrm{s}$ velocity. The reason for such effects arises due to the flow phenomenon over the blade. It is mainly due to the three dimensional flow over the blade. The effect of 3 dimensional flow around the blade is maximum at its first half i.e. from $r / S=0 \%$ to $r / S=50 \%$ because of its greater surface area. The remaining part, i.e. tip of the blade is also having 3 dimensional flow effects, but its strength is comparatively lower than the first half. Comparing blade with and without fence the \% of increase in power can be seen clearly. The blade with and without fence shows $7 \%-11.8 \%$ of increase in power production. However an extensive study of the height of the fence $(\mathrm{L} / \mathrm{T})$ is necessary to optimize the fence location.

A similar trend had been observed for 9 and $11 \mathrm{~m} / \mathrm{s}$ velocities in which fence installed at $\mathrm{r} / \mathrm{S}=0.5$ prove better than the other locations is shown in Figures 9-11.

\subsection{Effect of $L / t-F e n c e$ Size on Power}

In order to optimise the effect of fence size, fence with 3 different sizes have been selected: $L / t=1, L / t=2$ and $\mathrm{L} / \mathrm{t}=3$ and placed at various span wise locations. Effect of Fence Location $(\mathrm{r} / \mathrm{S})$ on Power have been studied and the results for $r / S=1$ have been reported in section 4.2. The blade set with fences of different sizes, $L / t=2$ and $\mathrm{L} / \mathrm{t}=3$ are shown in Figure 12 \& Figure 13 respectively.

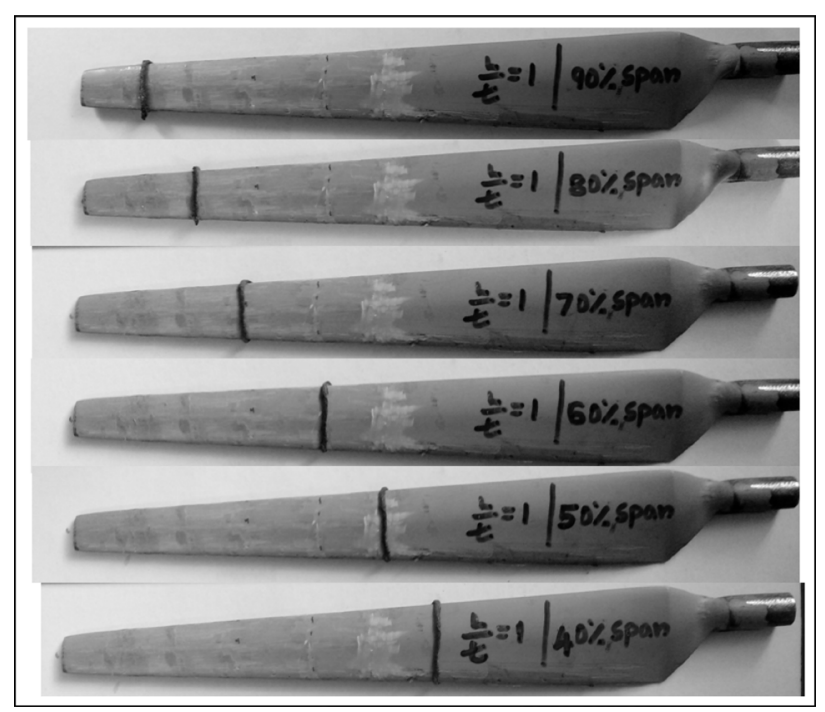

Figure 8. $\mathrm{L} / \mathrm{t}=1$ fence located from $40 \%$ to $90 \%$ of blade span.

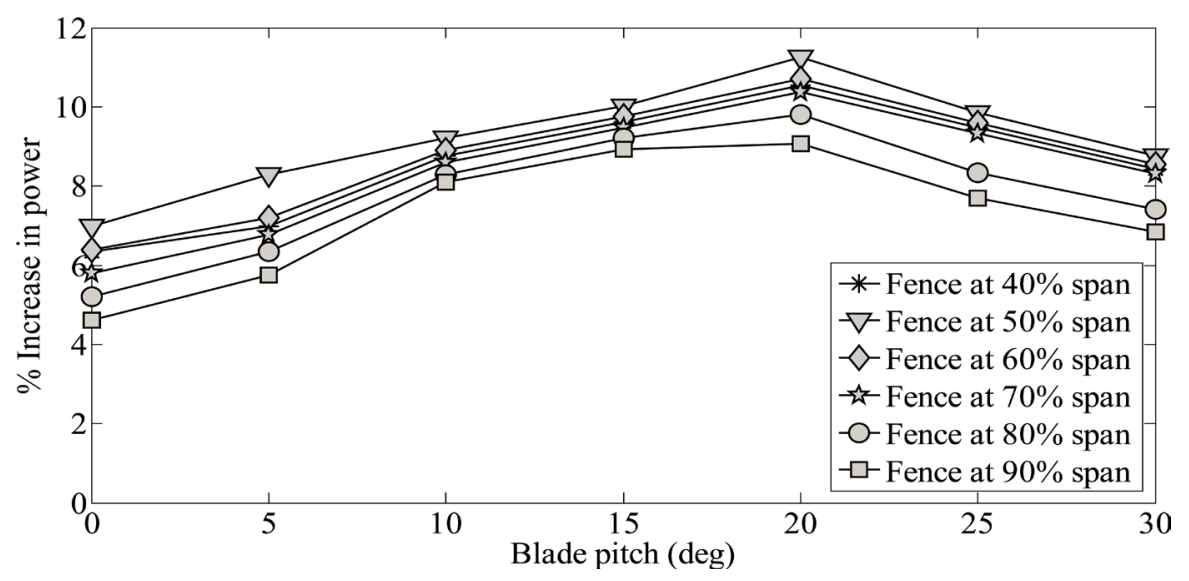

Figure 9. Effect of r/S on power at $7 \mathrm{~m} / \mathrm{s}$ for $700 \mathrm{ohms}$. 


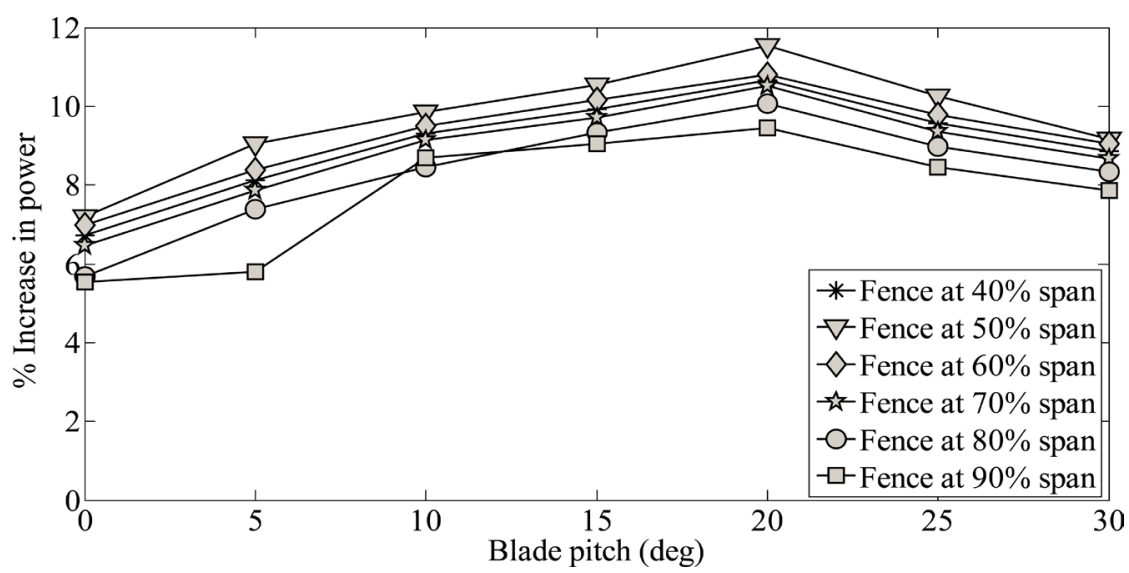

Figure 10. Effect of r/S on power at $9 \mathrm{~m} / \mathrm{s}$ for $700 \mathrm{ohms}$.

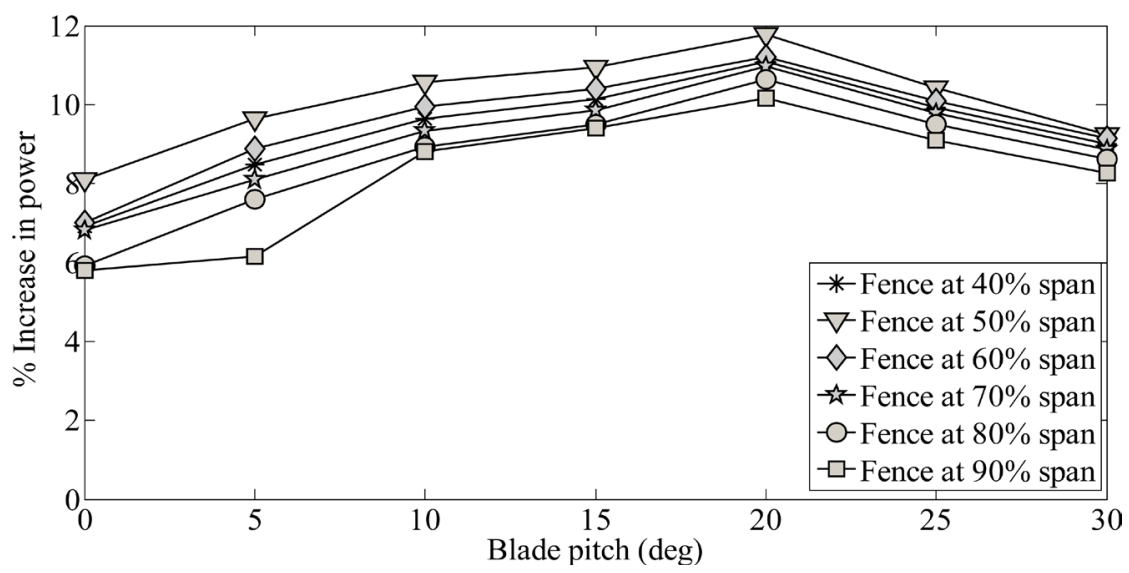

Figure 11. Effect of $\mathrm{r} / \mathrm{S}$ on power at $11 \mathrm{~m} / \mathrm{s}$ for $700 \mathrm{ohms}$.

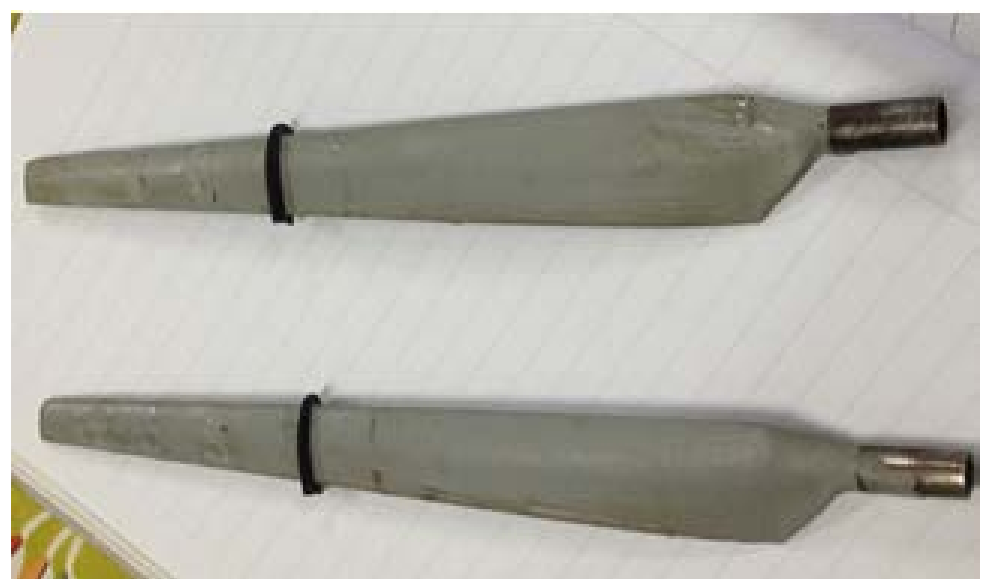

Figure 12. $\mathrm{L} / \mathrm{t}=2$ blade set with $2 \mathrm{~mm}$ fence.

Similar to section 4.2, the tests were carried out for blade set with fences $\mathrm{L} / \mathrm{t}=2 \mathrm{\&} \mathrm{L} / \mathrm{t}=3$ in the spanwise locations $40 \%, 50 \%, 60 \%, 70 \%, 80 \%$ and $90 \%$. Though the results are found to be optimum at 50\% spanwise location, the comparison for $\mathrm{L} / \mathrm{t}=1,2$ and 3 were presented in Figures 14-16 for 50\% location, $7 \mathrm{~m} / \mathrm{s}$ free stream velocity and 700 ohms resistance. From the graphs 14, 15 and 16, it is evident that fence with L/t $=1$ stands out when compared with $\mathrm{L} / \mathrm{t}=2$ and 3 . The maximum increase in power is found in 20 degree pitch angle for all the cases. Also it is inferred that, when the fence size increase beyond $\mathrm{L} / \mathrm{t}=1$, the power decreases. Maximum of 
$11.88 \%$ increase in power is recorded at $20 \%$ blade pitch at $11 \mathrm{~m} / \mathrm{s}$ velocity for configuration with $\mathrm{L} / \mathrm{t}=1$. Configutrations with $\mathrm{L} / \mathrm{t}=2$ and $\mathrm{L} / \mathrm{t}=3$ produce $9.67 \%$ and $8.12 \%$ increase in power respectively. From the results, it can be concluded that the fence $L / t=1$ is the optimum.

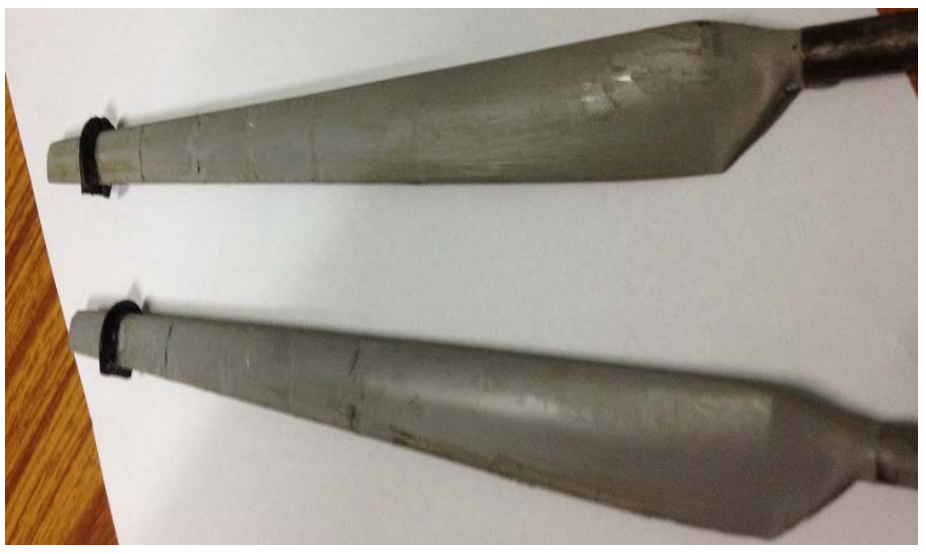

Figure 13. $\mathrm{L} / \mathrm{t}=3$ blade set with $3 \mathrm{~mm}$ fence.

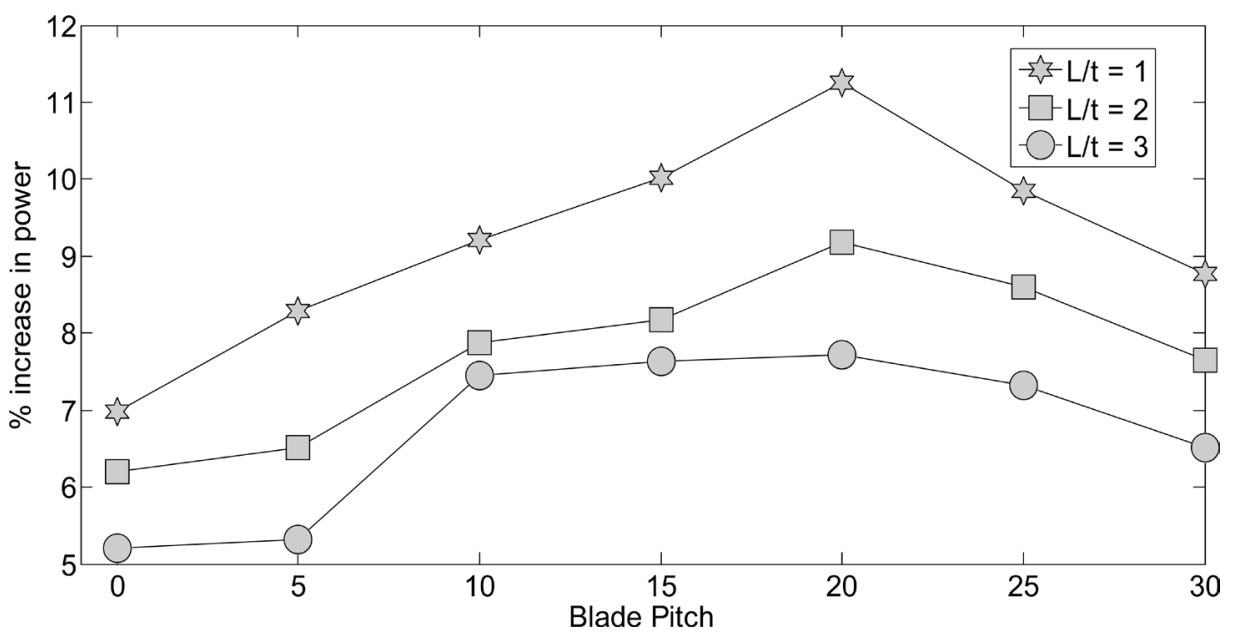

Figure 14. Effect of $\mathrm{L} / \mathrm{t}$ on power at $7 \mathrm{~m} / \mathrm{s}$ for $700 \mathrm{ohms}$ at $50 \%$ span.

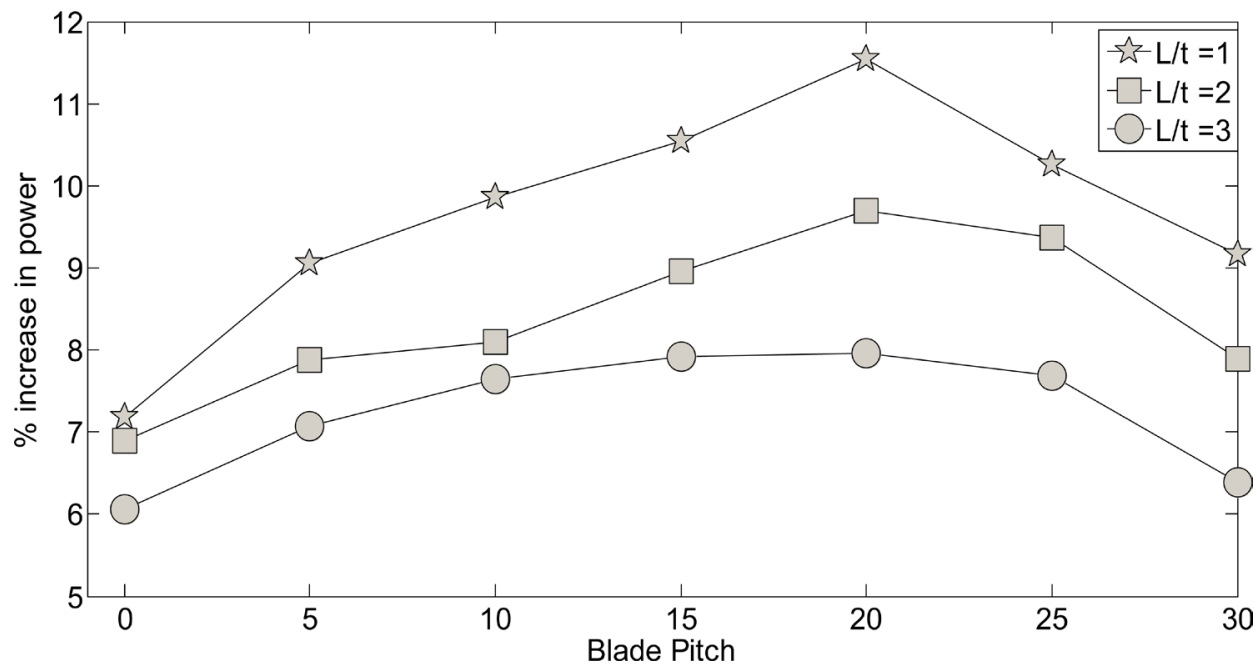

Figure 15. Effect of $\mathrm{L} / \mathrm{t}$ on power at $9 \mathrm{~m} / \mathrm{s}$ for $700 \mathrm{ohms}$ at $50 \%$ span. 


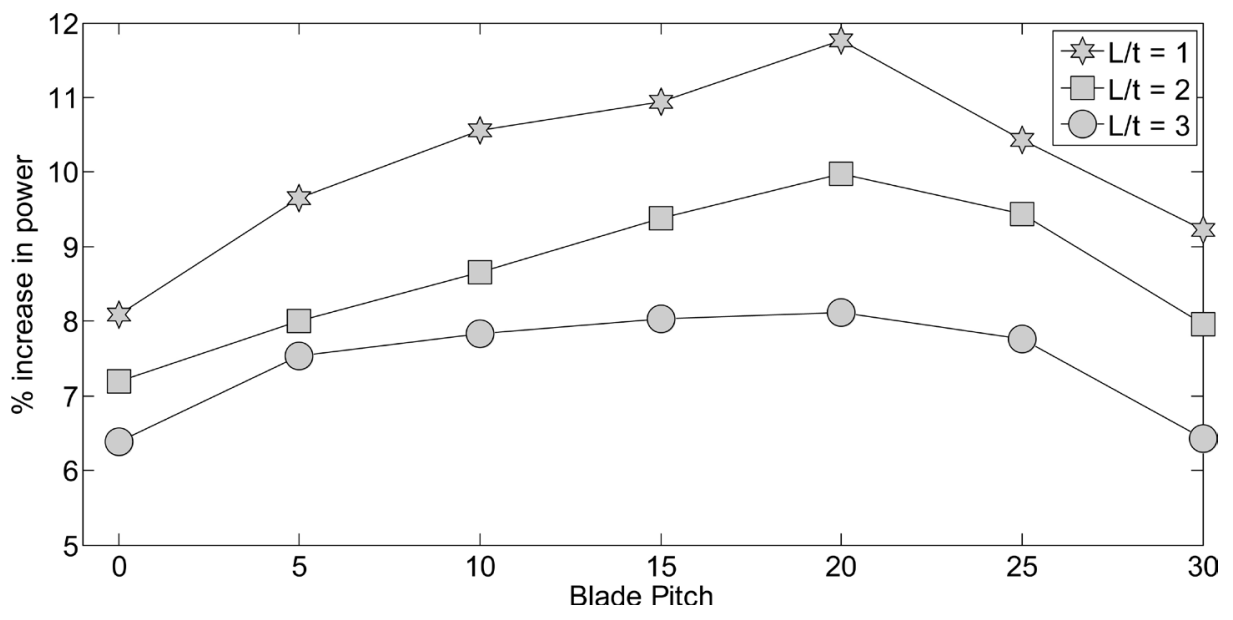

Figure 16. Effect of $\mathrm{L} / \mathrm{t}$ on power at $11 \mathrm{~m} / \mathrm{s}$ for 700 ohms at $50 \%$ span.

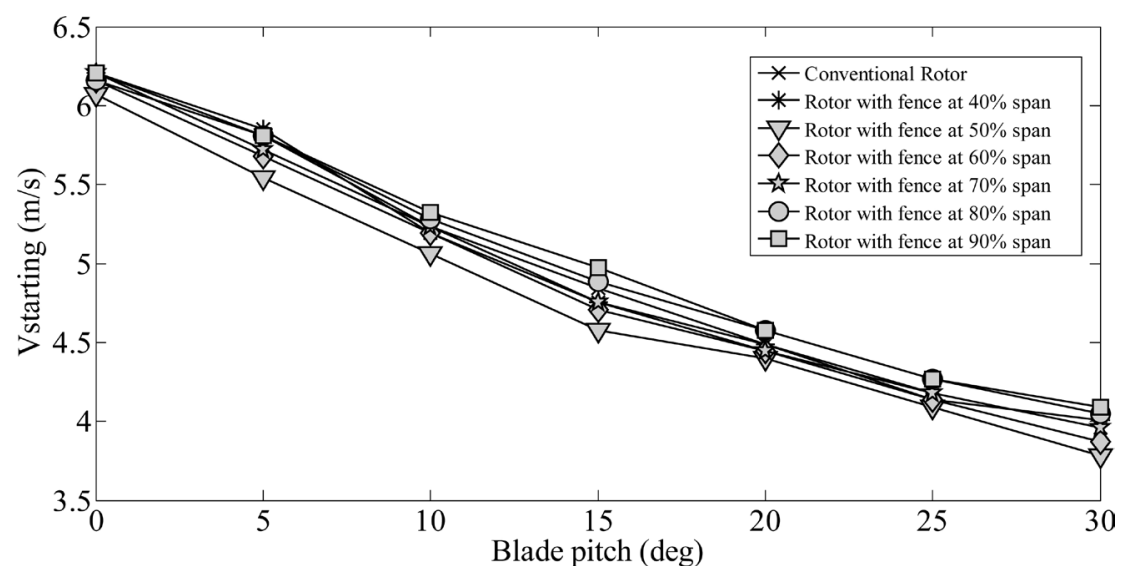

Figure 17. Effect of r/S on starting wind velocity.

\subsection{Effect of Starting Wind Velocity}

The starting wind speed is one of the pertinent key aspects among the wind turbine technologies. The start-upspeed is the minimum wind speed needed for the blades to begin spinning. Lower the start up speed greater will be the power production. Generally, various active and passive devices have been used by researchers to influence the startup speed. However, the fence effect will influence without trading off the performance. In this research influence of fence contributes to the earlier start up speed. At $50 \% \mathrm{r} / \mathrm{S}$, it is observed that the starting velocity is lower than the conventional rotor blade model as shown in Figure 17. It proves that the rotor with fence at $\mathrm{r} / \mathrm{S}=0.5$ keeps the lowest starting velocity compared to other $\mathrm{r} / \mathrm{S}$ locations. At 15 degree pitch angle, the conventional rotor blade starts at $5.2 \mathrm{~m} / \mathrm{s}$, whereas the rotor with fence at $50 \%$ starts at a free stream velocity of $4.75 \mathrm{~m} / \mathrm{s}$ which is $8.65 \%$ decrease. This is due to the 3 dimensional flows accumulate much on the bottom of the blade with $50 \%$ of the fence. In summary the pressure difference is increased and the lift component and the torque component have been initiated at much lower wind speeds. When the stating wind velocity is compared for configurations for different $\mathrm{L} / \mathrm{t}$ ratios, the rotor with fence at $\mathrm{L} / \mathrm{t}=1$ starts earlier than $\mathrm{L} / \mathrm{t}=2 \mathrm{and} \mathrm{L} / \mathrm{t}=3$. It is shown in Figure 18.

\section{Conclusions}

The wind tunnel experiments carried out on the conventional wind turbine blade and the blade with boundary layer fence revealed the influence of boundary layer fence in power production. Results show that the influence of blade fence and its effect on power production has been discussed in detail. The major conclusions are:

1) Wind turbine rotor with boundary layer fence exhibits better performance than the conventional wind turbine 


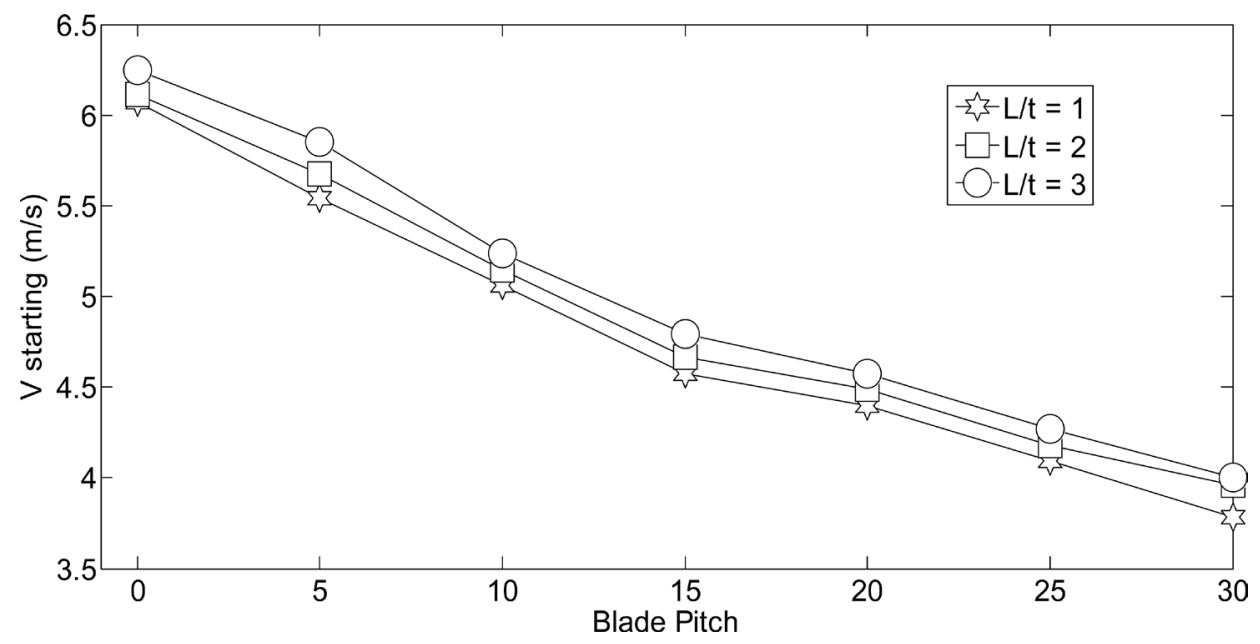

Figure 18. Effect of LIT on starting wind velocity at $\mathrm{r} / \mathrm{s}=50 \%$.

rotor model. Maximum of about $11.8 \%$ increase in the power had been obtained with the use of blade fence.

2) The blades with span wise fence locations show significant increase in power. This is most likely due to the physical flow phenomena, where the 3-Dimensional flow has been effectively controlled, which results in increased pressure difference, in turn increases the RPM and hence the increase in 11.8\% (at maximum) of power is obtained.

3) From the results, it is observed that maximum increase in $11.8 \%$ of power is obtained at the pitch angle of $20 \%$.

4) Investigation of fence location studied from $40 \%$ to $90 \%$ of the span wise length endows that the efficiency is predominant at $50 \%$ of fence location.

5) It is evident from the results that fence with $L / t=1$ stands out when compared with $L / t=2$ and 3 to produce the maximum power increase of $11.8 \%$.

6) Moreover, the starting speed of the wind turbine is decreased by $8.65 \%$ due to the inclusion of fence in conventional rotor. Concussive, the pressure difference is increased and the lift component and the torque component have been initiated at much lower wind speeds.

7) In addition to increase in percentage of power, the fence $L / t=1$ at $50 \%$ span wise location records earlier starting speed.

\section{References}

[1] Johansen, J., et al. (2008) Increased Aerodynamic Efficiency on Wind Turbine Rotors Using Winglets. 26th AIAA Applied Aerodynamics Conference, Honolulu, 18-21 August 2008, AIAA 2008-6728. http://dx.doi.org/10.2514/6.2008-6728

[2] IEA, Technology Road Map: Wind Energy. http://www.iea.org/papers/2009/wind_roadmap.pdf

[3] Ezio, S. and Claudio, C. (1998) Exploitation of Wind as an Energy Source to Meet the World's Electricity Demand. Wind Engineering and Industrial Aerodynamics, 74-76, 375-387. http://dx.doi.org/10.1016/S0167-6105(98)00034-8

[4] Mostafaeipour, A. (2010) Productivity and Development Issues of Global Wind Turbine Industry. Renewable and Sustainable Energy Reviews, 14, 1048-1058. http://dx.doi.org/10.1016/j.rser.2009.10.031

[5] IEA (2008) Energy Technology Perspectives: Scenarios and Strategies to 2020. http://www.iea.org/textbase/nppdf/free/2008/weo2008.pdf

[6] Saidur, R., Rahim, N.A., Islam, M.R. and Solangi, K.H. (2011) Environmental Impact of Wind Energy. Renewable and Sustainable Energy Reviews, 15, 2423-2430. http://dx.doi.org/10.1016/j.rser.2011.02.024

[7] Islam, M.R., Mekhilef, S. and Saidur, R. (2013) Progress and Recent Trends of Wind Energy Technology. Renewable and Sustainable Energy Reviews, 21, 456-468. http://dx.doi.org/10.1016/j.rser.2013.01.007

[8] Taehwan, C. and Kim, C.(2014) Wind Tunnel Test for the NREL Phase VI Rotor with 2 m Diameter. Renewable Energy, 65, 265-274. http://dx.doi.org/10.1016/j.renene.2013.10.009

[9] Botasso, C.L. (2014) Wind Tunnel Testing of Scaled Wind Turbine Models: Beyond Aerodynamics. Journal of Wind Engineering and Industrial Aerodynamics, 127, 11-28. http://dx.doi.org/10.1016/j.jweia.2014.01.009 
[10] Baerwald, E., D’Amours, G., Klug, B. and Barclay, R. (2008) Barotrauma Is a Significant Cause of Bat Fatalities at Wind Turbines. Current Biology, 18, R695-R696.

http://www.sciencedirect.com/science/article/pii/S0960982208007513

[11] Merchant, S. (2010) Wind Tunnel Analysis of a Wind Turbine with Winglets. 2010 ECTC Proceedings of ASME Early Career Technical Conference, Tulsa, 25-27 March 2010.

[12] Johansen, J. and Sorensen, N.N. (2006) Aerodynamic Investigation of Winglets on Wind Turbine Blades Using CFD. Risø-R-1543(EN), Risø National Laboratory, Roskilde.

[13] Williams, M.D. (2009) Wind Tunnel Analysis and Flight Test of a Wing Fence on a T-38. Master of Science Thesis, Air Force Institute of Technology, Wright-Patterson Air Force Base, Ohio.

[14] Kim, B., Kim, W., Bae, S., Park, J. and Kim, M. (2011) Aerodynamic Design and Performance Analysis of Multi-MW Class Wind Turbine Blade. Journal of Mechanical Science and Technology, 25, 1995-2002. http://dx.doi.org/10.1007/s12206-011-0521-X

[15] Li, J., Chen, J.Y. and Chen, X.B. (2010) Aerodynamic Response Analysis of Wind Turbines. Journal of Mechanical Science and Technology, 25, 89-95. http://dx.doi.org/10.1007/s12206-010-0909-z

[16] Chen, Y.-P. (2011) A Study of The Aerodynamic Behavior of a NREL Phase VI Wind Turbine Using the CFD Methodology. Master of Science Thesis, Wright State University, Fairborn.

[17] Predescu, M., Bejinariu, A., Mitroi, O. and Nedelcu, A. (2009) Influence of the Number of Blades on the Mechanical Power Curve of Wind Turbines. International Conference on Renewable Energies and Power Quality (ICREPQ'09), Valencia, 15-17 April 2009, 519.

\section{Nomenclature}

NREL: National Renewable Energy Laboratory

TSR: Tip Speed Ratio

DRB: Decade Resistance Box

$\mathrm{C}_{\mathrm{p}}$ : Power Coefficient

$V_{00}$ : Free Stream Velocity $(\mathrm{m} / \mathrm{s})$

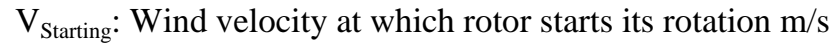

AFC: Active Flow Control

PFC: Passive Flow Control

$\mathrm{r}$ : distance along the spanwise direction in blade (m)

$S$ : Radius of rotor (m)

L: Length of the Fence projected normal to the Blade (mm)

$\mathrm{t}$ : Thickness of the Fence (mm)

$\mathrm{P}_{\mathrm{U}}$ : Power produced by the upgraded rotor blades (w)

$\mathrm{P}_{\mathrm{C}}$ : Power produced by the baseline rotor blades $(\mathrm{w})$ 